\title{
KAĞIT KATKILI FARKLI SERAMİK BÜNYELER ÜZERINNDE RAKU UYGULAMALARI
}

Araştırma Makalesi / Research Article

\begin{tabular}{l|l} 
Sağlıyan Sönmez, Ö., Kılınç Mirdalı, N., Halefoğlu, & Geliş Tarihi: 01.02.2021 \\
Y. Z. (2021). Kağıt Katkılı Farklı Seramik Bünyeler & Kabul Tarihi: 18.05.2021 \\
Üzerinde Raku Uygulamaları Nevşehir Hacı Bektaş & \\
Veli Üniversitesi SBE Dergisi, 11(2), 820-828. & E-ISSN: 2149-3871
\end{tabular}

Öğr. Gör. Özlem SAĞLIYAN SÖNMEZ

Nevşehir Hacı Bektaş Veli Üniversitesi, Avanos Meslek Yüksekokulu ozlemsagliyan@nevsehir.edu.tr ORCID No: 0000-0002-8084-657X

Dr. Öğr. Üyesi Nergis KILINÇ MIRDALI

Çukurova Üniversitesi, Güzel Sanatlar Fakültesi, Seramik Bölümü nergismirdali@gmail.com

ORCID No: 0000-0003-0581-5914

Doç. Dr. Yusuf Ziya HALEFOĞLU

Çukurova Üniversitesi, Güzel Sanatlar Fakültesi, Seramik Bölümü yhalefoglu@gmail.com

ORCID No: 0000-0001-9871-0956

\begin{abstract}
ÖZ
Raku düşük sıcaklıkta yapılan ve raslantısal olarak redüksiyon aşamasında farklı renk efektleri ile sonuçlanan hızlı bir seramik pişirim sürecidir. Tarihsel olarak ilk Momoyama Dönemi’nde (1573-1615), Japonya'nın Kyoto şehrinde geliştirilen özellikle Zen Budistlerinin çay töreninde kullandıkları seramik ürünler için tasarlanmış ve geliştirilmiştir. Kâğıt katkılı seramik bünye olarak adlandırılan "Paper Clay", seramik çamurlarına farklı çeşit ve miktarda kâğıtlar ilave edilerek oluşturulan bir karışımdır. Su ile ıslatılarak seramik çamurlarına karıştırılan kâğıt, çamur içerisinde homojen bir şekilde dağıtılır. Ayrıca kağıt katkısı seramik bünyelerde gözenekli bir yapıya sebep olduğu için raku sırını bünyeye daha fazla emerek raku sır pişirim sonrası yüzeyde farklı metalik etki ve renk efektleri oluşturmaktadır. Bu çalışmada sanatsal açıdan raku sırının kağıt katkılı seramik bünyeler üzerinde sanatsal, farklı, özgün renk efektleri elde edilmiştir. Bu çalışmada kırmızı, beyaz ve şamotlu seramik çamuruna \%10 kâğıt katkısı ilave edilmiştir. Hazırlanan kağıt katkılı bünyeler üzerinde bakır oksit, demir oksit ve kobalt oksitli 3 farklı raku sırları uygulanmıştır. Sonuç olarak farklı efektler elde edilmiştir.
\end{abstract}

Anahtar Kelimeler: Seramik, Raku pişirimi, Paper Clay.

\section{RAKU APPLICATIONS ON DIFFERENT PAPER ADDITIVE (PAPER CLAY) CERAMIC BODIES}

\section{ABSTRACT}

Raku is a rapid ceramic firing process, which is made at low temperature and results in different color effects in the reduction phase. It was historically developed in the first Momoyama Period (1573-1615), especially designed for ceramic products used by Zen Buddhists in the tea ceremony and "Paper Clay", which is called as paper-added ceramic body, is a mixture created by adding different types and amounts of paper to ceramic clay. The paper, which is wetted with water and mixed into ceramic slurries, is distributed homogeneously in the mud. In this study, $10 \%$ paper additive was added to red, white and chamotte ceramic clay. 3 different raku glazes with copper oxide, iron oxide and cobalt oxide were applied on the prepared paper-added bodies. As a result, different effects were obtained.

Keywords:Ceramic, Raku Firing, Paper Clay. 


\section{GİRIŞ}

Raku'nun Japonların geleneksel seramiklerinde kullanılan farklı pişme sonuçlarına açık bir seramik sırlama tekniği olarak, 400 yıl önce Japonya'da geliştirildiği bilinmektedir. Kelime anlam olarak ise "memnuniyet, zevk, rahatlık ve neşe" anlamlarına gelmektedir. Raku tekniğini ilk uygulayan seramikçi Cociro isimli Japon bir çömlekçidir. Japonya'da ortaya çıkan raku geleneği batıya Bernard Leach ve Paul Solder gibi seramik sanatçılarının seramiklerinde raku sırını kullanarak popülerleştirmesi ile aktarılmıştır (Aris, 2015: 8). Raku uygulaması yapmak için beyaz, kırmızı, şamotlu ve porselen gibi her çeşit kil kullanılmaktadır (Sherrill 2016: 2-4). Batı' da yapılan raku uygulamaları Doğudaki uygulamalardan çok farklıdır; fakat raku pişirim sonrasında elde edilen sonuçlar ile seramikçiye vermiş olduğu güzellik ve enerji ile sonsuz çeşitlilik sunmaktadır (Watkins and Wandless 2006). Bir redüksiyon pişirim yöntemi olarak raku pişirimi seramik sanatçıları tarafından çok kullanılan bir yöntem olup, çamurda ve sırda renk değişikliği ve çamur içindeki alkalilerin etkilerini oluşturur. Redüksiyon teriminin kimyasal anlatımı, oksijen iyonlarının azalmasıdır. Bu değer azalmasından dolayı "indirgenme" olarak isimlendirilir. Bu indirgenme (redüksiyon) esnasında bir indirgeyici (redükleyici) maddenin varlığ 1 gerekmektedir. Bu madde, indirgenme esnasında oksijenle birleşir ve okside olur. Redüksiyon seramik alanında, yanma havasının az olduğu fırın ortamında pişirmenin yapılması ve yüksek değerli oksitlerin düşük değere indirgenmesi sonucu oluşur (Arcasoy ve Başkırkan, 2020: 324-326). Redüksiyonlu pişirim için mangan ve demirin üç değerli oksitlerinin yeterli oranda zengin olması aranmaktadır. $\mathrm{Bu}$ oksitlerden demir oksit $\left(\mathrm{Fe}_{2} \mathrm{O}_{3}\right)$, doğada hammaddelerin içerisinde en çok bulunan oksittir ve aynı zamanda çok belirgin renk değişikliklerine yol açar. Demir oksit $\left(\mathrm{Fe}_{2} \mathrm{O}_{3}\right)$, seramik kamara firınlarda, yakıtın az miktarda hava ile yakılmasında, oluşan redüksiyon aracısı karbonmonoksit (CO) ile indirgenir:

$$
\mathrm{Fe}_{2} \mathrm{O}_{3}+\mathrm{CO} \rightarrow 2 \mathrm{FeO}+\mathrm{CO}_{2} \text { (eşitlik 1) }
$$

Redüksiyonlu pişirimde, seramik çamur içinde bulunan eriticiler, daha etkili olduklarından dolayı, seramik çamurunun yumuşaması da artar. Bundan dolayı klinker ve sertçini çamurlarının düşük sıcaklıkta redüksiyonlu pişirimlerinde sinterleme sağlanır. $\mathrm{Bu}$ tür seramiklerde çamur kalınlığı çok olduğundan, redüksiyonun etki süresini iyi ayarlamak gerekir. Kısa sürdürülen reaksiyonda, redüksiyon çamurun içine işlemeyeceği için ürünün dış kısımları redüksiyon, iç kısımları ise oksidasyon rengi gösterir. Bu olayın tam tersi olursa, yani yeteri sürede sürdürülen redüksiyondan hemen sonra, oksidasyon yapılırsa, işte bu olaya "reoksidasyon" denir. Böylece seramik çamur iç kısımda redüksiyon dış kısımda oksidasyon rengi gösterir. Redüksiyonlu pişirime en elverişli seramik fırınlar, açık ateşle yakılan kamara fırınlarıdır (Baycık, 2003: 71).

Günümüzde seramik çamurlarında, atık durumdaki veya geri dönüşüme uğramamış kâğıt parçaları geleneksel çamur bünyelere karıştırılmak suretiyle dayanıklılık, esneklik ve ağırlığı hafifletme maksatlı kullanılmaktadır. Kâğıt katkılı seramik bünyenin geçmişi tahmini olarak 45-50 yıl civarındadır. 1975'te kâğıt katkılı seramik yapım uygulamaları Rosette Gault tarafindan devam ettirilmiştir. Böylece yapılan bu çalışmalar ile günümüzde kâğıt hamurunu kil katkısı olarak kullanması ile çömlek ve heykel formlarında Robert Roucsenberg bir proje için Hindistan'da olduğu sırada paçavra çamuru diye isimlendirilen bir malzeme kullanarak seramik bünyeye kâğıdı eklemiştir (Frisinger, 2012: 31). Hindistan da yapılan bu çalışma ile birlikte kâğıt katkılı seramik bünyeler daha fazla kullanılmaya başlanmış ve gelişme kaydedilmiştir. Yakın zamanda da gelişen fiber (lif) takviyeli kil kullanımı da 1989 yılında araştırmaya başlamış ve 1990'ların başlarında bu araştırma önemli değişiklikler yapabilmeyi mümkün kılmaya başlamıştır (Watkins and Wandless 2006).

Kâğıt katkılı seramik bünye hazırlamak için, tuvalet kâğıdı, havlu kâğıt ve gazete kâğıdı temeli oluşturan daha kısa liflere sahip ürünler kullanmak daha uygundur. Bu kâğıtlar sıcak suda kolayca parçalanır. Naylon, cam elyafı ve talaş gibi diğer malzemeler kil ile karıştırılmıştır; ancak etkisi kâğıt katkısına benzememiştir. Selüloz lifi, tüm bitki ve ağaçların önemli bir parçası olan içi boş tüp benzeri bir yapıdır. Selüloz, bir sünger gibi davranarak nemi kendi içine hapsetme kabiliyetine sahiptir. Böylece kâğıt lifleri (selüloz), bünyeye ciltleme özelliklerini daha da artıran, 
seramik çamuruna pürüzsüz, hafif dikenli bir yüzey vermektedir. Bu bitki maddesinin çürümesini önlemek için kâğıt hamuru gerektiği gibi karıştırılabilir veya plastik torbalarda derin dondurucuda saklanabilir (Frisinger, 2012: 31).

Kil ve kâğıt hamuru birbirine karıştı̆̆ında kil trombositleri, elyaf tüplerine kolayca sokulur. Elde edilen karmaşık elyaf ve kil karışımı çömlekçilere ve heykeltıraşlara sıra dışı çalışma özellikleri sağlamaktadır (Gartside, 1993: 32). Bu malzeme normalden daha esnek olmas1 nedeniyle kil bünye için vazgeçilmez öneme sahip bir katkı malzemesine dönüştürmektedir. Kâğıt lif kil içine karıştırıldığı vakit, düzensiz, delikli, su emici tüp benzeri lifler kil bünye içerisinde suyu emmektedir. Esnek, delikli lifler kuruma veya yeniden islanma sürecinde büzüştügünde, kil bünyeyle birlikte çekmekte ve genleşmektedir. Kâğıt hamuru kil ile karıştırıldığında, sıvı mum halini almakta olup, içindeki sertleşmiş partiküller kemik sertliğinde veya bisküvi pişiriminde mikro gözeneklerle gayet iyi etkileşmektedir. Bu sayede sanatçı aşırı kurumuş kil eser üzerinde özgürce kırılma, çatlama olmadan uygulamalar ve değişiklikler gerçekleştirebilmektedir (Takka, 2014: 6-25).

Kâğıt katkılı bünye hazırlamak için herhangi bir kil kullanılabilir. Karışım pürüzsüz ve kremsi olana kadar iyice karıştırılmalıdır. Kil kurudukça büyük çatlakların oluşması neredeyse imkânsızdır. Alçı kalıplarda kâğıt katkılı çamur şekillendirme için uygundur. Malzeme kurudukça inanılmaz gerilme mukavemeti geliştirir. Böylece seramik parçalar daha büyük ve daha güçlü olabildiği gibi ağırlıkça da \% 50'ye kadar daha hafif olabilir (Holmes, 2010: 5-7).

\section{MATERYAL VE METOT}

\subsection{Materyal}

Döküm Çamuru: İçerisinde kaolin, kil, kuvars ve kalktaşı gibi hammaddelerden oluşan, 930-980 ${ }^{\circ} \mathrm{C}$ pişme aralığına sahip, pişme sonrası kırılganlığ yüksek ve beyaz renkli döküm çamurudur (Arcasoy ve Başkırkan, 2020: 324-326). Döküm çamurunun kimyasal analizi (\%) çizelge 1'de verilmiştir (Coşkun vd. 2015: 414-420).

Çizelge 1: Döküm çamurunun kimyasal analizi

\begin{tabular}{|l|l|}
\hline Oksitler & $\begin{array}{l}\text { Miktar } \\
\text { (\%Ağırlıkça) }\end{array}$ \\
\hline $\mathrm{SiO}_{2}$ & 65,64 \\
\hline $\mathrm{Al}_{2} \mathrm{O}_{3}$ & 21,42 \\
\hline $\mathrm{CaO}$ & 0,44 \\
\hline $\mathrm{MgO}$ & 0,28 \\
\hline $\mathrm{K}_{2} \mathrm{O}$ & 1,18 \\
\hline $\mathrm{Fe}_{2} \mathrm{O}_{3}$ & 0,65 \\
\hline $\mathrm{TiO}_{2}$ & 0,53 \\
\hline $\mathrm{Na}_{2} \mathrm{O}$ & 4,07 \\
\hline $\mathrm{P}_{2} \mathrm{O}_{3}$ & 0,12 \\
\hline
\end{tabular}

Şamotlu Çamur: Diğer seramik çamurlarına oranla pişme sonrası mukavemeti oldukça yüksek olan çamur bileşimi kil ve şamot karışımından oluşmaktadır. Pişme sıcaklık değeri 900 $1200{ }^{\circ} \mathrm{C}$ 'de pişme sonrası renginde beyazdan sarıya, griden kırmızıya kadar değişim göstermektedir (Açar, 2011: 10). Şamotlu çamurun kimyasal analizi (\%) Çizelge 2'de verilmiştir (Musil and Waltraud, 2014: 907-915). 
Çizelge 2: Şamotlu çamurunun kimyasal analizi

\begin{tabular}{|l|l|}
\hline Oksitler & $\begin{array}{l}\text { Miktar } \\
\text { (\%Ağırlıkça) }\end{array}$ \\
\hline $\mathrm{SiO}_{2}$ & 60,06 \\
\hline $\mathrm{Al}_{2} \mathrm{O}_{3}$ & 26,43 \\
\hline $\mathrm{CaO}$ & 0,23 \\
\hline $\mathrm{MgO}$ & 0,80 \\
\hline $\mathrm{K}_{2} \mathrm{O}$ & 2,29 \\
\hline $\mathrm{Fe}_{2} \mathrm{O}_{3}$ & 3,31 \\
\hline $\mathrm{TiO}_{2}$ & 1,03 \\
\hline $\mathrm{SO}_{3}$ & 0,22 \\
\hline
\end{tabular}

Kırmızı Çamur: Çamur bileşimi kalk kum tanecikleri ve demirli killerden oluşan kırmızı çamur $900-1180^{\circ} \mathrm{C}$ 'de pişmektedir. Pişme sonrası rengi koyu pembeden koyu kırmızıya değişim göstermektedir (Açar, 2011: 10). Avanos kırmızı kilinin kimyasal analizi (\%) Çizelge 3'de verilmiştir (Genç vd., 2017: 71-90).

Çizelge 3: Kırmızı çamurun kimyasal analizi

\begin{tabular}{|l|l|}
\hline Oksitler & $\begin{array}{l}\text { Miktar } \\
\text { (\%A ğırlıkça) }\end{array}$ \\
\hline $\mathrm{SiO}_{2}$ & 48,83 \\
\hline $\mathrm{Al}_{2} \mathrm{O}_{3}$ & 16,80 \\
\hline $\mathrm{CaO}$ & 8,34 \\
\hline $\mathrm{MgO}$ & 3,05 \\
\hline $\mathrm{Na}_{2} \mathrm{O}$ & 1,21 \\
\hline $\mathrm{K}_{2} \mathrm{O}$ & 4,23 \\
\hline $\mathrm{Fe}_{2} \mathrm{O}_{3}$ & 6,09 \\
\hline $\mathrm{MnO} \mathrm{O}$ & 0,09 \\
\hline $\mathrm{TiO}_{2}$ & 0,66 \\
\hline $\mathrm{P}_{2} \mathrm{O}_{5}$ & 0,16 \\
\hline
\end{tabular}

Kaolen: Kaolen seramik endüstrisinin en çok tercih ettiği hammaddelerden biridir. Saf alümina ve silis içermektedir. Tek başına kullanıldığında, ergime sıcaklığı yüksek olduğundan 1sıya karşı direnç gösterir. Pişme rengi içerdiği renklendirici metal oksitlerin cinsi ve miktarına bağlı olarak sarı, krem ve beyaz renklerde değişebilmektedir (Kibici, 2002: 59-76).

Feldispat: Seramik çamurlarında en çok kullanılan hammaddelerden birisi 'feldspatlardır'. Potasyum feldspat ve sodyum feldspat seramik çamurda önemli derecede eritici özelliğe sahiptir. Tek başlarına doğal bir sır özelliğindedir (Tiryaki, 2014: 15). 
Kuvars: Kuvars seramik çamurlarına sıcaklık dayanımı kazandırmak için eklenmektedir (Birks, 1997).

Selüloz: Yeşil yapraklı bitkilerde ve ağaçlarda fotosentezin doğal bir yan ürünü olan selüloz lifi birçok kâğıdın da temel malzemesidir. Selüloz kâğıt yapımında bir hammadde olarak kullanılabilmesine imkân veren lifsel yapısı ve hücre yapısındaki farklıl1klar nedeniyle farklı kâğıtların elde edilmesi bakımından kağıt endüstrisinde büyük önem taşmaktadır (Atik, 1999: 1922).

Araştırma kapsamında oluşturulan deneysel uygulamalar, demir oksit, kobalt oksit ve bakır oksit içeren üç farklı raku sırı ve \%10 selüloz katkılı şamotlu, kırmızı ve döküm çamuru ile oluşturulmuş bünyelere uygulanarak elde edilmiştir. Raku sırları $870{ }^{\circ} \mathrm{C}-1090{ }^{\circ} \mathrm{C}$ sicaklık aralıklarında eriyebilen sırlar olarak seramikçiler tarafından tercih edilen sırlardır. Raku sırları kullanılan ergiticilere bağlı olarak kurşunlu veya alkali sırlar olarak da sınıflandırılabilir. Genellikle raku sırları camsı parlak bir görünümde olup, soğutma sırasında çatlamaya eğilimli sırlardır. Birçok raku sırının cezbedici yanı, yüksek sıcaklıklarda elde edilmesi mümkün olmayan renklerin, renklendiriciler ilave edilerek düşük derecelerde parlak ve geniş bir renk aralığında albenisi yüksek sırların elde edilebilmesini sağlamaktadır (Aydın 2018: 6-7).

\subsection{Metod}

Beyaz, kırmızı ve şamotlu çamurların 900 gr kuru tartımları yapılmış ve ayrı kaplar içerisinde su ile çözülmeye alınmıştır. Ayrı bir yerde seramik çamurlarına eklenecek olan kâğıt malzemenin kuru tartımı (100 gr) yapılmıştır. Su ile çözülmeye bırakılıp açıcıdan geçirilerek belirli bir kıvama getirilen kâğıt, farklı seramik çamurlarına belirli oranlarda ilave edilmiştir. Her bir seramik çamuru ayrı ayrı karıştırıcıdan geçirilerek homojen bir kıvam elde edilmiştir. Hazırlanan çamurdan deneme tabletleri yapılmış ve 9 adet deneme tabletinin $980{ }^{\circ} \mathrm{C}$ sıcaklıkta bisküvi pişirimi gerçekleştirilmiştir.

Reçeteleri hazırlanan üç farklı raku sırı hassas terazide $1 \mathrm{~kg}$ tartımları yapıldıktan sonra seramik sır değirmenlerine alınarak, 2'şer saat öğ̈ütülmüştür. Değirmenden alınan raku sırları eleklerden geçirilerek temiz kaplara konulmuştur. $980{ }^{\circ} \mathrm{C}$ elektrikli seramik fırınında bisküvi pişirimi yapılmış, deneme tabletlerinin fırça yardımı ile sırlaması yapılmışıır. Sırlanan deney tabletlerinin doğal gazlı raku firınına uygun şekilde konularak $980{ }^{\circ} \mathrm{C}$ 'de raku pişirimi gerçekleştirilmiştir. 3 saat sonunda $980{ }^{\circ} \mathrm{C}$ 'ye ulaşan raku fırını içerisinden raku sırlı seramik deneme tabletleri bir maşa yardımı ile hızla alınarak redüksiyon çukuruna bırakılmış ve bu işlem sırasında redüksiyon çukuruna her konan ürün sonrasında üzerine az miktarda talaş ve gazete kâğıdı atılarak redüksiyon ortamı için kâğıtların yanması sağlanmıştır. En son üründe redüksiyon çukuruna konulduktan sonra 1-5 dk yanma sağlanmış, redüksiyon çukurunun kapağı kapatılarak redüksiyon için bırakılmıştır. Yaklaşık 3 saat sonrası redüksiyon çukurunun kapağı açılmış ve kül içerisindeki ürünler bir maşa yardımı ile alınarak suyun içerisine bırakılmıştır. Soğuması tamamlanan ürünler fırça yardımı ile temizlenerek suyun içerisinden alınmıştır. Aynı işlemler, 980 ${ }^{\circ} \mathrm{C}^{\prime}$ de bisküvi pişirimi yapılmış olan sanatsal formlar üzerinde de tekrarlanmıştır.

\section{BULGULAR}

Farklı bünyeler üzerinde raku sırının uygulanması ile ilgili araştırmalara, düşük sıcaklıklarda eriyebilen hammaddelerin seçimiyle başlanmıştır. Elde edilen sır reçetelerine ayrı ayrı renklendirici oksitlerden olan demir oksit, kobalt oksit ve bakır oksit farklı oranlarda ilave edilerek, raku sır karışımları bilyeli değirmende öğütülmüştür. Araştırmada kullanılan raku sır seger formülasyon aralıkları ve oluşturdukları renk/efektler Çizelge $4^{\prime}$ te verilmiştir. $980{ }^{\circ} \mathrm{C}$ pişirim sonucunda elde edilen raku sırlarına ait görsel sonuçlar Şekil 1 ve Şekil 2'de görülmektedir. 
Çizelge 4: Raku sırlarına ait Seger formülasyon aralıkları: a) 1. Grup bakır oksit (CuO) katkılı; b) 2. Grup demir oksit $\left(\mathrm{Fe}_{2} \mathrm{O}_{3}\right)$ katkıl1, c) 3. Grup kobalt oksit (CoO) katk1lı sırlar

\begin{tabular}{|c|c|c|c|}
\hline $\begin{array}{l}\text { Örnek } \\
\text { Kodu }\end{array}$ & Bileşen & $\begin{array}{l}\text { Seger Aralığı } \\
(\mathrm{mol})\end{array}$ & Renk/Efekt \\
\hline 1.Grup & $\begin{array}{c}\mathrm{RO}(\mathrm{CaO}, \mathrm{CuO}, \mathrm{PbO}) \\
\mathrm{R}_{2} \mathrm{O}\left(\mathrm{Na}_{2} \mathrm{O}, \mathrm{K}_{2} \mathrm{O}\right) \\
\mathrm{R}_{2} \mathrm{O}_{3}\left(\mathrm{Al}_{2} \mathrm{O}_{3}, \mathrm{~B}_{2} \mathrm{O}_{3}\right) \\
\mathrm{RO}_{2}\left(\mathrm{SiO}_{2}\right)\end{array}$ & $\begin{array}{l}0,543 \\
0,457 \\
1,002 \\
0,737\end{array}$ & Turkuaz- metalik \\
\hline 2.Grup & $\begin{array}{c}\mathrm{RO}(\mathrm{CaO}) \\
\mathrm{R}_{2} \mathrm{O}\left(\mathrm{Na}_{2} \mathrm{O}\right) \\
\mathrm{R}_{2} \mathrm{O}_{3}\left(\mathrm{Al}_{2} \mathrm{O}_{3}, \mathrm{~B}_{2} \mathrm{O}_{3} \mathrm{Fe}_{2} \mathrm{O}_{3}\right) \\
\mathrm{RO}_{2}\left(\mathrm{SiO}_{2}\right)\end{array}$ & $\begin{array}{l}0,310 \\
0,690 \\
1,800 \\
1,025\end{array}$ & $\begin{array}{l}\text { Kiremit kırmızısı- } \\
\text { metalik }\end{array}$ \\
\hline 3.Grup & $\begin{array}{c}\mathrm{RO}(\mathrm{CaO}, \mathrm{PbO}, \mathrm{CoO}) \\
\mathrm{R}_{2} \mathrm{O}\left(\mathrm{Na}_{2} \mathrm{O}\right) \\
\mathrm{R}_{2} \mathrm{O}_{3}\left(\mathrm{Al}_{2} \mathrm{O}_{3}, \mathrm{~B}_{2} \mathrm{O}_{3}\right) \\
\mathrm{RO}_{2}\left(\mathrm{SiO}_{2}\right)\end{array}$ & $\begin{array}{l}0,820 \\
0,180 \\
0,700 \\
1,079\end{array}$ & Mavi, turkuaz- metalik \\
\hline
\end{tabular}

1., 2., ve 3. grup raku sırı uygulamaları üç farklı bünye üzerine uygulanmıştır. Raku sır pişirimi doğal gazlı raku firınında $980^{\circ} \mathrm{C}$ 'de ve 3 saat süre ile yapılmıştır.

1. grup raku sırı kâğıt katkılı (paper clay) döküm çamuru ile oluşturulan bünye üzerinde iyi tutunmuş, sır reçetesine katılan bakır oksit sıra metalik turkuaz renk vermiş, kapatıcı, parlak bir raku sırı oluşmuştur (Şekil 1-a). Kırmızı bünye üzerine uygulanmış sır bakır kırmızı ve daha fazla metalik etki vermiş, kapatıcı, parlak bir raku sırı oluşmasına sebep olmuştur (Şekil 1-b). Şamotlu seramik bünye üzerine uygulandığında raku sırı pişirim sıcaklığında deformasyona uğramış ve çatlamalar meydana gelmiştir. Ancak uygulandığı bünye üzerinde koyu metalik kapatıcı bir görünüm elde edilmiştir (Şekil 1-c).

2. grup raku sırı kâğıt katkılı (paper clay) bünye üzerinde iyi tutunmuş, sır reçetesine katılan demir oksit sıra metalik renk vermiş, kapatıcı, parlak bir raku sırı oluşturmasına sebep olmuştur (Şekil 1-d). Kırmızı bünye üzerinde raku sırı açık kahve ve kızılımsı parlak etki vermiştir (Şekil 1-e). Şamotlu seramik bünye üzerinde metalik parlak ve kapatıcı bir görünüm sergilemiştir (Şekil 1-f).

3. grup raku sırı kâğıt katkılı (paper clay) döküm çamuru ile oluşturulan bünye üzerinde sır reçetesine katılan kobalt oksit sıra turkuaz yeşili renk vermiş, kapatıcı, parlak bir raku sırı oluşmuştur (Şekil 1-g). Kırmızı bünye üzerinde açık krem, sarı ve yer yer metalik etki vermiştir (Şekil 1-h). Şamotlu seramik bünye üzerinde lacivert ve kobalt mavisi renkte, metalik parlak özellikte görüntü sergilemiştir (Şekil 1-1). 

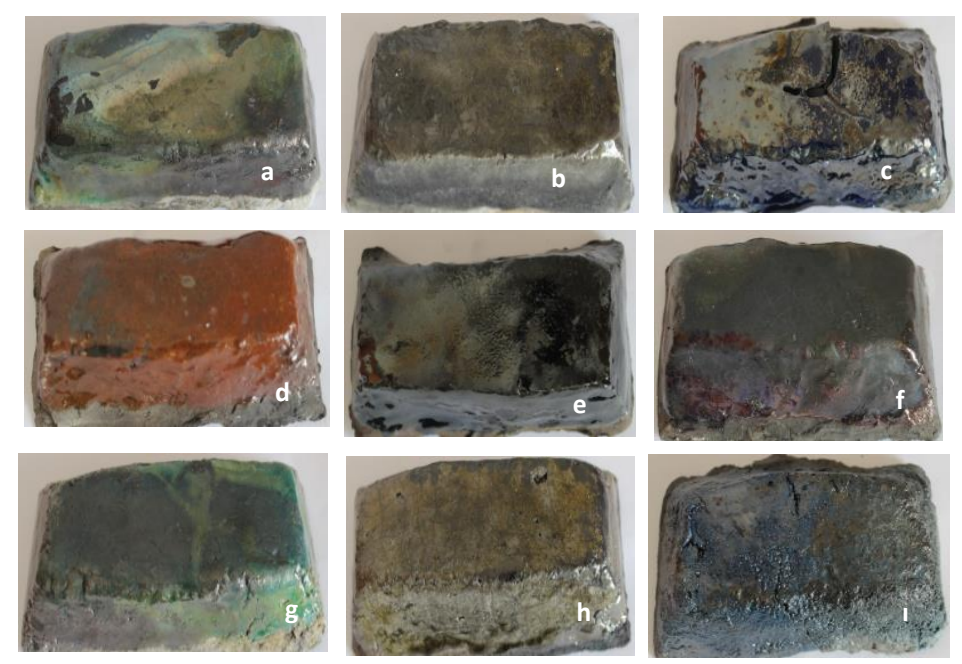

Şekil 1. $980{ }^{\circ} \mathrm{C}$ 'de seramik gazlı raku fırınında 3 saatlik raku sır pişirimi sonrası elde edilen kağıt katkılı (Paper Clay) beyaz, kırmızı ve şamotlu bünyeler ile oluşturulmuş deneme tabletleri: a)Kağıt katkılı döküm çamuru ile oluşturulan bünye üzerine uygulanmış 1. Grup bakır oksit (CuO) katkılı raku sırı $(\mathrm{KBRCu})$, b) Kağıt katkılı kırmızı bünye üzerine uygulanmış 1. Grup bakır oksit (CuO) katkılı raku sırı $(\mathrm{KKRCu})$, c) Kağıt katkılı şamotlu bünye üzerine uygulanmış 1. Grup bakır oksit $(\mathrm{CuO})$ katkılı raku sırı $(\mathrm{KSRCu}) \mathrm{d}) \mathrm{Kağıt} \mathrm{katkılı} \mathrm{döküm} \mathrm{çamuru} \mathrm{ile} \mathrm{oluşturulmuş} \mathrm{bünye} \mathrm{üzerine} \mathrm{uygulanmış} \mathrm{2.} \mathrm{Grup} \mathrm{demir} \mathrm{oksit}$ $\left(\mathrm{Fe}_{2} \mathrm{O}_{3}\right)$ katkılı raku sırı (KBRFe), e) Kağıt katkılı kırmızı bünye üzerine uygulanmış 2. Grup demir oksit $\left(\mathrm{Fe}_{2} \mathrm{O}_{3}\right)$ katkılı raku sırı (KKRFe), f) Kağıt katkılı şamotlu bünye üzerine uygulanmış 2. Grup demir oksit $\left(\mathrm{Fe}_{2} \mathrm{O}_{3}\right)$ katkılı raku sırı (KSRFe), g) Kağıt katkılı döküm çamuru ile oluşturulan bünye üzerine 3. Grup kobalt oksit (CoO) katkılı raku sırı (KBRCo), h) Kağıt katkılı kırmızı bünye üzerine uygulanmış 3 . Grup kobalt oksit (CoO) katkılı raku sırı (KKRCo) ve 1) Kağıt katkılı şamotlu bünye üzerine uygulanmış 3. Grup kobalt oksit (CoO) katkılı raku sırı (KSRCo).

\section{SONUÇ}

$\mathrm{Bu}$ çalışmada, üç farklı raku sır reçetesi üç farklı kağıt katkılı seramik çamurundan oluşturlmuş deneme tabletleri üzerine uygulanmış ve $980{ }^{\circ} \mathrm{C}$ raku sır pişirimleri yapılmıştır. Yapılan bu uygulamalar sonucunda raku sırlarının seramik bünyeler üzerinde farklı renk etkileri verdiği gözlemlenmiştir. Uygulama sonuçları her bünye üzerinde olumlu sonuçlar vermiştir. Raku pişirimi sonrasında seramik bünyeler üzerinde istenilen parlak, metalik raku sır efektleri oluştuğu gözlemlenmiştir. Uygulama yapılan tabletler üzerinde deformasyonlar olduğu gözlemlenmiştir. \% 10 kağıt katkı1ı şamotlu seramik bünye üzerinde bünyedeki kağıdın verdiği o fazla gözeneklerden kaynaklı olarak deformasyonlar olduğu gözlemlenmiştir. Diğer bünyelerde ise bu şekilde bir deformasyon olmadığı gözlenmiştir. Bu deformasyonun oluşmaması için şamotlu kile \%10 oranından daha az selüloz katılarak kağıt katkılı bir bünye hazırlanması daha sağlıklı olabilir.

Bakır oksit katkılı raku sırının üç seramik tablet yüzeyinde de parlak, metalik turkuaz renk efekti verdiği gözlemlenmiştir. Demir oksitli raku sırı ise kırmızı bünye üzerinde açık kahve ve kızılımsı parlak etki vermiştir. Döküm çamuru ile oluşturulmuş bünye ve şamotlu bünye üzerinde ise daha siyaha yakın koyu metalik bir etki oluşturduğu görülmüsstür. Kobalt oksitli raku sırı kırmızı seramik bünye üzerinde açık krem, sarı ve yer yer metalik etki vermiştir. Şamotlu seramik bünye üzerinde lacivert ve kobalt mavisi renkte, metalik parlak özellikte görüntü sergilemiştir. Döküm çamuru ile oluşturulan bünye üzerinde ise turkuaz yeşil, parlak ve şeffaf bir sır tabakası oluştuğu görülmüştür.

Sanatsal olarak farklı ve özgün metalik renk etkisi oluşturulmak isteniyorsa bu çalışmada hazırlanan raku sırları ve \%10 luk kağıt katkılı seramik bünyeler bu amaca uygun olabilmektedir. Ayrıca renk efektleri her seramik bünyede yüzey üzerinde değişik efektler verdiği için sanatçıya daha özgün sonuçlar verebileceği de düşünülmektedir. 
Sonuçlar değerlendirildiğinde üç farklı seramik bünyeye ilave edilen kağıt katkısının bünyeler de gözenekli yapı oluşturduğu, böylece kağıt katkılı seramik bünyelerin pişme sonrası raku sır kalınlığının fazla olduğu gözlemlenmiştir. Bu da raku sırının normal tüm yüzeyde aynı metalik ve parlak etki yerine; yüzey üzerinde farklı, özgün, metalik renk efektleri vermesine sebep olmuştur.

\section{KAYNAKÇA}

Açar, P. (2011). Kağıt Katkllı Seramik Bünyelerin İncelenmesi ve Seramik Uygulamaları, Yayınlanmış Yüksek Lisans Tezi, Sakarya Üniversitesi Sosyal Bilimler Enstitüsü, Sakarya.

Arcasoy, A. ve Başkırkan, H. (2020). Seramik Teknolojisi, İstanbul: Literatür Yayıncılık.

Aris, K. N. M. (2015). The Influence and Remaining Japanese Cultural Elements in Raku Artworks of Contemporary Non Japanese Artists/Potters. The IAFOR Academic Review, V.1, (2), 8-15.

Atik, C. (1999). Geri Dönüşümün Selüloz Lifleri Üzerindeki Etkileri, Yayınlanmış Doktora Tezi, İstanbul Üniversitesi Fen Bilimleri Enstitüsü, İstanbul.

Aydın, K. (2018). Toplanmalı Sirların Seramik Form ve Yüzeylere Uygulanması, Yayınlanmış Yüksek Lisans Tezi, Hacettepe Üniversitesi Güzel Sanatlar Enstitüsü, Ankara.

Baycık, S. (2003). Granüle Yüksek Fırın Curuflarının Karo Sektöründe Kullanılabilirliğinin Araştırılması, Yayınlanmış Yüksek Lisans Tezi, İTÜ Fen Bilimleri Enstitüsü, İstanbul.

Birks, T. (1997). The Complete Potter's Companion, London.

Coskun .N. D, Iş̧1k E., Şahin A., Börekçioğlu, Ç. ve Uz, V. (2015). Yüksek Poroziteli Beyaz Pişen Seramik Çamurunun Karakterizasyonu. Afyon Kocatepe Üniversitesi Fen ve Mühendislik Bilimleri Dergisi, 15, 414420.

Frisinger, L. A. (2012). Paperclay in Recent South African Ceramics: Continuity and Change in Studio Works, Degree of Master, University of KwaZulu-Natal.

Gartside, B. (1993). Mix What with Clay?. New Zealand Potter, 35 (1), 32.

Genç, S. , Öz, G., Tan, Ö., Kılıç, K. S. ve Oruç, E. (2017). The Search on The Use Of Avanos Clay Within The Structure Of Plastic Clay, Slip, Color And Glaze $\left(1000^{\circ} \mathrm{C}, 1200^{\circ} \mathrm{C}\right)$. 11. Uluslararası Eskişehir Pişmiş Toprak Seтроzуити, 71-90.

Holmes, M. (2000). Paperclay, National Ceramics Quarterly. Issue 51, 5-7.

Kibici, Y. (2002). Porselen Üretimi ve Kullanılan Hammaddelerin Teknolojik Özellikleri, Seramik Hammaddeleri ve Teknolojik Özellikleri. Afyon: Afyon Kocatepe Üniversitesi Yayınları, Yayın No:41.

Musil S. S. and Waltraud M. K. (2014). In Situ Mechanical Properties of Chamotte Particulate Reinforced, Potassium Geopolymer. J. Am. Ceram. Soc., 97 [3], 907-915.

Sherrill, J. R. (2016). How to Raku, Successful Tips and Techniques for Raku Firing, 2-4.

Takka, U. (2014). Kağıt Katkılı Bünyede Yöre Astarının Kullanımı, Yayınlanmış Yüksek Lisans Tezi, Süleyman Demirel Üniversitesi Güzel Sanatlar Enstitüsü, Isparta.

Tiryaki, V. (2014). Sağllk Gereçleri Döküm Çamurunda Tane Boyutu Değişiminin Fiziksel ve Pişme Özelliklerine Olan Etkisi, Yayınlanmış Yüksek Lisans Tezi, Dumlupınar Üniversitesi Fen Bilimleri Enstitüsü, Kütahya.

Watkins, J. C. and Wandless, P. A. (2006). Alternative Kilns \& Firing Techniques. USA: A Lark Ceramics Book. 


\section{EXTENDED SUMMARY}

\section{Purpose}

In this study, $10 \%$ paper additive was added to red, white and chamotte ceramic clay. The results were examined by applying 3 different raku glazes with copper oxide, iron oxide and cobalt oxide on the prepared paper-added bodies. Raku is a rapid ceramic firing process, which is made at low temperature and results in different color effects in the reduction phase. It was historically developed in the first Momoyama Period (1573-1615), especially designed for ceramic products used by Zen Buddhists in the tea ceremony and "Paper Clay", which is called as paper-added ceramic body, is a mixture created by adding different types and amounts of paper to ceramic clay. The paper, which is wetted with water and mixed into ceramic slurries, is distributed homogeneously in the mud.

\section{Methodology}

The experimental applications created within the scope of the research were obtained by applying three different raku glaze containing iron oxide, cobalt oxide and copper oxide and $10 \%$ cellulose-added chamotte, red and white bodies. 9 pieces of $10 \%$ cellulose-added trial tablets were made and biscuit fired in 980 . Then, they were glazed with raku glaze and raku fired in 980 for 3 hours in a gas raku oven. After the raku firing, it was left to oxidize in the oxidation pit for 2 hours.

\section{Results}

In this study, 3 different raku glaze recipes were applied on trial tablets made of ceramic mud with 3 different paper additives and $980 \mathrm{C}$ raku glaze firing was done. The application results gave positive results on each body. It has been observed that the copper oxide-added raku glaze gives a shiny, metallic turquoise color effect on the surfaces of the three ceramic tablets. Raku glaze on the red body has a light brown and reddish shiny effect. On the white and chamotte body, it has a metallic effect that is closer to black. It has a light cream, yellow and metallic effect on the red body. The chamotte ceramics exhibited a dark blue and cobalt blue color, metallic shiny appearance on the body.10\% paper-added chamotte ceramics were observed to have deformations on the body due to heat and excessive pores formed from paper fill in the body, and no such deformation was observed in other bodies.

\section{Conclusion and Discussion}

As a result of these applications, it has been observed that the raku glaze, which is used as artistic, gives different color effects on the ceramic bodies prepared with 3 different $10 \%$ celluloseadded red, white and chamotte ceramic slurries. The chamotte ceramic gives a blue-cobalt metallic color effect on the body. It has been observed that the red ceramic body gives a light creamy metallic effect due to the iron oxide in the clay. The iron oxide raku glaze gives a brown-red metallic color effect on the surface in the white ceramic body, while the red and chamotte ceramic It was observed that the copper oxidized raku glaze gave a color effect close to metallic turquoise in all three bodies. If it is desired to create a different and original metallic color effect artistically, the raku glaze prepared in this study and ceramic bodies with $10 \%$ paper additive can be suitable for this purpose.In addition, color effects can give the artist more original results as they give different effects on the surface of each ceramic body. In addition, it is seen that there are deformations on the chamotte ceramic body due to the cellulose additive. It may be healthier to prepare a paper-added body by adding less than $10 \%$ cellulose to the chamotte clay to prevent deformation. 